\title{
Ilinka Terziyska
}

\section{One-Day Cultural Tours in Bulgaria: A Netnography Study of Customer Satisfaction}

\section{Abstract}

The aim of this study is to identify the salient attributes of one-day cultural tours provided by ground operators. The research is based on the netnography approach, using as a main data source user-generated content (UGC) on TripAdvisor. A total of 233 reviews were processed applying thematic analysis through the $\mathrm{R}$ package for Qualitative Data Analysis (RQDA). Following an open coding procedure, five dimensions of service experience, possibly connected to tourist satisfaction were identified - the quality of tour guiding, the overall organization of the trip, sites visited, comfort of transport vehicles, and value for money. In practical terms, the findings will be of use to tour operators for designing a competitive product. As research on customer satisfaction regarding organized tours is limited, especially when one-day tours are concerned, this paper contributes to better understanding of the factors that affect it. The study complements existing knowledge of tourist satisfaction by providing insight and a model specifically tailored to one-day cultural tours, which are a growing segment in tour operator activities. The main limitation of the study is connected with the method used - it identifies salient attributes and prioritizes them, but cannot describe the nature and strength of the impact.

Keywords: day tours, salient attributes, satisfaction, netnography, cultural tours, thematic analysis, Bulgaria

\section{Introduction}

With the entering of low-budget airlines on the Bulgarian market, in recent years the number of short-term trips of non-residents to the country (and the capital city of Sofia in particular) has been on the rise (Dogramadjieva et al., 2019). Quite often, these are tourists who organize their trip by themselves but would benefit from the services of the so-called ground tour operators. Typically, these companies are concentrated in large urban centers, where the number of individual foreign tourists is the largest - in the case of Bulgaria this includes Sofia, Plovdiv, Varna, Veliko Tarnovo. Their typical market segment includes tourists who do not have their own means of transport during their stay in the destination, or lack sufficient knowledge of the region, which often makes the tour operator company the only possible intermediary for exploring the local culture of destinations outside the place of arrival.

Given the rapid growth of this travel segment, there is an evident need of a deeper insight into the main factors that determine the success of the products on offer and consequently - the effective operation of the business as a whole. In this respect, achieving consumer satisfaction is crucial for gaining competitive positions and achieving long-term favourable positions in the market. Satisfied tourists share their positive experiences with others, creating beneficial word-of-mouth and are inclined to re-visit the destination (Shafiee et al., 2016; Kuo et al., 2016; Marcussen, 2011). The main questions in this sense are: "What creates a sense of satisfaction for the tourist" and "Which basic constructs must be taken into account when analyzing tourist satisfaction". While there are a number of studies on the relation between tour guiding and tourist satisfaction (Huang et al. 2009; Chang K.-C. , 2012; Chan et al. 2015; Kuo et al., 2016; Çetinkaya \& Öter, 2016), the majority of them are based on quantitative research, with only a few authors employing qualitative approaches to identify determinant factors (Chang J.-C., 2009). This paper aims to fill this gap by exploring salient product

Ilinka Terziyska, PhD, Corresponding author, Department of Tourism, South West University Neofit Rilski, Blagoevgrad, Bulgaria; ORCID ID: https://orcid.org/0000-0001-8445-0727; e-mail: lynnterziyska@gmail.com

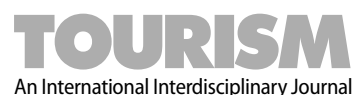


attributes through a qualitative method (i.e. netnography), focusing on a particular type of tours - one-day cultural tours, targeted mainly at foreign tourists.

\section{Literature review}

In the scientific literature in the sphere of consumer behavior, satisfaction is the final stage of a process beginning with the identification of needs and ending with an assessment of the already consumed product (Peter, 1996). Customer satisfaction is defined as: "...the consumer's fulfilment response. It is a judgment that a product or service feature, or the product or service itself, provided (or is providing) a pleasurable level of consumption-related fulfilment, including levels of under- or over-fulfilment." (Oliver, 1997, p. 13), with three focal determinants: expectations, performance, and subjective disconfirmation. The definition of MacKay and Crompton is similar; they, however, draw attention to the "psychological outcome of the service experience" (MacKay \& Crompton, 1990). Johnson et al. (1995) also take into account these two approaches, calling them transaction and cumulative. In the transaction approach, the focus is on the encounter of the buyer and the service provider, and the cumulative satisfaction refers to the entire consumption process and results from the assessment of a number of holiday elements (travel, overnight, entertainment, etc.), as well as the tourist's expectations before and during the trip.

There is a common agreement in literature that individual factors that affect consumer satisfaction can be different in nature. They are usually divided into the following groups:

(1) Satisfiers - their absence does not have a negative effect, but if they are present, the level of satisfaction increases;

(2) Dissatisfiers - their high quality does not lead to satisfaction, but low levels lead to dissatisfaction;

(3) Critical - factors that have a serious positive or negative impact;

(4) Neutral - their influence on the level of customer satisfaction is negligible. (Johnston, 1995).

The above four groups are based on Kano's customer satisfaction model (Kano et al., 1984). The different nature of the influence of the factors according to this model is expressed in non-linearity, i.e. only in the case of critical factors, the relationship between quality improvement and satisfaction is straightforward. Also called "three-factor theory of consumer satisfaction," this model opposes the traditional representation of relative significance only in numerical form, and significance is seen as a function of performance (Matzler, 2004).

The Kano Model enables a more accurate prioritization of product development solutions. If, for instance, must-be factors are at a satisfactory level, they are of low priority for intervention, as improving their quality would not lead to a proportional increase in the level of satisfaction. On the other hand, the poor performance of the attractive (excitement) ones does not have a negative impact, but investing in this direction could provide a serious source of competitive advantage. A product that satisfies only must-be and one-dimension requirements is considered to be easily replaceable and does not usually stand out from competition.

The Kano model is one of the most frequently used ones, including in tourism studies. Yet, some authors raise the question of how adequately it is used in specific cases, especially when it is paired with IPA analysis (Mikulić \& Prebežac, 2016).

Customer satisfaction has received a lot of attention in the scientific literature in the sphere of tourism too. Most of the studies aim to develop tools to measure satisfaction with product features, often in order to identify the relative importance that tourists attribute to each of them, compared to the overall level of satisfaction (e.g. cleanliness, comfort, customer service). Such information is important for the tourism industry, especially with regard to the development of the tourist product and its quality improvement. Different types of tourism have also been the subject of numerous studies. Ross and Isa-Ahola (1991), for example, study 
satisfaction from cultural tours, while $\mathrm{Lu}$ and Stepchenkova (2012) explore the attributes of satisfaction related to ecotourism based on content analysis of Trip Advisor reviews. Consumer satisfaction within the framework of wine tourism is also a popular topic, especially in the light of its relation to motivation and loyalty (Brandano et al., 2019).

Factors influencing the choice of organized versus independent travel are also subject of study, generally divided into two groups - objective (age, education, gender, length of stay, group size, price) and subjective (previous experience, motivation). While not explicitly devoted to satisfaction, but rather to decision-making, one of the first studies to focus on the differences between package and non-package travel is the one of Hsieh et al. (1994). Based on sociodemographic and travel characteristics, and information sources, the authors proposed a comparative profile taking into account travel philosophy, benefit sought, and product preference. More than a decade later, Laesser (2008) identified the following leading determinants for choosing a package trip: familiarity with the destination, small group, new experience, comfort and the opportunity to pamper yourself, more time for yourself. Other researchers focus on satisfaction from the individual aspects of the journey, e.g. hotels (Saleh \& Ryan, 1992), (Heide et al., 1999), or restaurants (Ryu et al., 2012; Liu \& Tse, 2018). Travel satisfaction with shopping has been studied by Rieslingen and Turner (2002). A number of authors (Chon \& Olsen, 1991; Kozak \& Rimmington, 2000; Joppe et al., 2001) have studied tourism satisfaction at the destination level, resulting in the elaboration of sets of attributes to measure the level of satisfaction and explain its antecedents. A recent study establishes a link between perceived functional benefit, hedonic benefit, symbolic benefit, affective evaluation and cognitive evaluation, and tourist satisfaction (Marinao, 2017).

There are several studies of satisfaction with package trips in the scientific literature. Bowie and Chang (2016) conducted a survey (based on participant observation) on tourist satisfaction of a multi-national group visiting Scandinavian destinations. The main antecedents of satisfaction identified by the authors are: expectations, customer attitude during the tour, hedonism, while recurring sources of complaints are: itinerary planning and arrangements, hotel choice, and group leader competence. Huang et al. (2009) divide the tourist satisfaction of package trips into three major aspects - satisfaction with the guiding service, satisfaction with the services included in the tour (auxiliary services), and overall satisfaction with the tour experience. Using the critical incident technique, Wang et al. (2000) developed one of the most comprehensive models of critical success factors for group package tours, consisting of 9 main factors (pre-tour briefing, airport/plane, hotel, restaurant, coach, scenic spot, shopping, optional tour, and others) and 25 sub-categories. A similar model is presented by Bowie and Chang (2016), where the pre-tour briefing is replaced with tour leader. The majority of studies devote special attention to the importance of the guide / tour leader. It is believed that their functions can be divided into four main groups: instrumental (related to their responsibility for the smooth running of the journey), social (responsibilities related to the psychological climate of the group), interactive (the role of mediator between tourists and the local population and institutions) and communication (selection of attractions and presentation of adequate information) (Cohen, 1985).

For decades, the study of customer satisfaction has been premised on the idea that "overall attitude is a function of beliefs about an object's attributes... and the evaluative aspect of these beliefs (i.e., the importance of the attribute to overall satisfaction with the object)" (Alpert, 1971, p. 185). There are a number of methods for identifying and prioritizing these attributes/factors, with the three most popular concepts applied being salience, importance and determinance.

One of the first terms used in connection with the influence of individual factors in making a purchase decision is salience. Krech and Cruchfield (1948) defined it as follows: "Saliency refers to the fact that not all of a man's beliefs stand out with equal prominence in his cognitive field. He may be more acutely aware of certain of his beliefs than others, they may enter his thoughts more readily, they may be more frequently verbalized - they are, in a word, salient." (p. 163). Salience is thought to be directly linked to satisfaction (Bordalo et 
al., 2013), based on the fact that it "refers to the phenomenon that when one's attention is differentially directed to one portion on the environment rather than to others, the information contained in that portion will receive disproportionate weighing in subsequent judgments." (Taylor \& Thompson, 1982). Most studies on tourist satisfaction are based on the assumption that the level of satisfaction is strongly dependent on the perceived performance of product/destination attributes (Kozak, 2003; Yoon \& Uysal, 2005; Bulatovic, 2020), although their impact can be different not only in strength, but also in nature (Alegre \& Garau, 2010).

One of the most commonly used methods for identifying salient product attributes is asking respondents to list the characteristics of the product in the order in which they come to their minds when considering a purchase. In recent years, the advent of digital technologies and the platforms for user-generated content (USG) have led to a new approach to identifying salient product attributes - through content/thematic analysis of customer reviews, sometimes also called customers' spontaneous comments (Tontini \& Bento, 2020). Examples of identifying salient attributes through analyzing frequency of mentions in online reviews (usually in TripAdvisor or Airbnb) include the studies of Guo et al. (2019) and Tussyadiah and Zach (2017), which are focused on peer-to-peer accommodation, and Xiang et al. (2015), based on guest experiences in hotel accommodations. All of these use big data analytics and have proven a strong association of salient attributes / consumer experience with satisfaction ratings through the employment of a mixed method approach. These findings are to some extent questioned by a recent study, where the relationship of spontaneous comments and the overall assessment of service quality was further confirmed, but it was also found out that "what customers spontaneously comment, may or may not influence their general evaluation of the service" (Tontini \& Bento, 2020, p. 6).

Applying text analytics for attribute and pattern extraction has its drawbacks too. Some of the concerns are related to loosing "valuable, often nuanced, information" in the data, which can be overcome by a qualitative analysis of a certain portion of reviews (Tussyadiah \& Zach, 2017, p. 649). So far, the only study that employs a purely qualitative approach to identifying determinants of customer satisfaction in tourism is the one of Bianchi, who employs the critical incidence technique to define satisfiers and dissatisfiers for solo holiday travelers (Bianchi, 2016). The present study tries to fill this gap by focusing on the qualitative interpretation of results.

Identifying salient attributes, or, in other words, the product attributes that stand out in consumer minds and influence their purchase decisions (MacMillan \& McGrath, 1996) is the necessary first step in measuring tourist satisfaction, because it is the backbone of the next one - determining the impact of individual factors on the overall satisfaction level.

The second concept - importance, is sometimes interchangeably used with salience (Alpert et al., 1977), but they are actually quite different. In order to identify the importance of the individual attributes, consumers would usually answer a direct question, formulated as follows: "How important are the following characteristics to you on a scale of 1 to 5?". This is the reason why it is often called stated importance. The derived importance, on the other hand, is defined by examining the correlation between the assessments of the individual characteristics and the overall level of satisfaction by applying statistical methods (e.g. regression analysis).

Derived importance is often seen as determinance. Myers and Alpert (Alpert et al., 1977) define determinance as the property of some product characteristics to have a greater influence on the formation of preferences and choices than others. According to them, determinism always refers to a specific case in which the characteristics of specific competing products are compared.

The main objective of this study is to elicit salient attributes of one-day cultural tours by using a netnography approach. Netnography studies of tourism satisfaction are still scarce (most UGC-based ones are highly quantified), although the employment of this method in the sphere of tourism and market research in general has increased in the last decade (Heinonen \& Medberg, 2018). While only one study focused explicitly on 
tourist satisfaction was found (Lu \& Stepchenkova, 2012), some examples of netnographic analysis of tourism experience (which is closely related to satisfaction) include the study by Erciyas and Yildiz (2018) on five-star hotels in Cappadocia and the one dedicated to the underlying dimensions of customer experience with resort brands, conducted by Ismail et al. (2010). Both of them are based on thematic analysis of online customer reviews and use NVIVO for data processing.

Up to the author's knowledge, there have been only two studies using netnography for identifying antecedents of satisfaction or tourist experience in cultural tours in Bulgaria so far. A study by Terziyska (2017), published in Bulgarian, identifies four major factors that affect customer satisfaction, based on thematic analysis of usergenerated content in TripAdvisor - tour guide, tour logistics, cultural/natural attractions and transport. This research has some serious drawbacks - it is limited solely to the identification of themes (satisfaction antecedents), the data is not coded, and the factors are not ranked in terms of significance. The other study that uses online reviews to analyze tourist experience of city tours in Sofia, Bulgaria is the one of Dogramadjieva et al. (2019). Using NVivo12, the authors applied open manual coding to a database of 849 reviews on TripAdvisor, resulting in the following key dimensions of a memorable tour experience: 1) the guide's skills and personality; 2) enjoyable learning and deeper understanding; 3) local experience and discovery; 4) fun and entertainment; 5) freedom and flexibility.

\section{Research design}

The study employs the netnography method, which is relatively new, but very suitable for "generating rich, thick description through grounded interpretations" (Kozinets \& Earley, 2014) and allows retrieval of detailed qualitative information. At the same time, it is not associated with high costs and loss of time.

The most frequent approaches used in netnography studies in tourism so far are thematic analysis, content analysis, and discourse analysis, with fewer authors reporting the use of sentiment analysis, narrative analysis, mapping and frequency analysis (Tavakoli \& Wijesinghe, 2019). Thematic analysis is "a method for identifying, analyzing, and reporting patterns (themes) within data" (Brown \& Clarke, 2006), which is considered an accessible and theoretically-flexible tool, especially for large sets of qualitative data. (Brown \& Clarke, 2006). While some other authors do not define it as a method, but rather as a tool that is used within different methods (Boyatzis, 1999), unquestionably, thematic coding is one of the most preferred approaches when the aim is to identify themes and categories and obtain structured information from mainly unstructured data. Based on this, thematic analysis was chosen as the most appropriate research tool in the current study.

In addition, there are two major approaches to coding qualitative data - 1) code definition is informed by previous research, or 2) themes/codes are completely derived from data. This study has taken the second approach (the categories are data-driven) and the findings are compared with existing research.

The platform that was chosen for collecting information is TripAdvisor because of its worldwide popularity and its high degree of reliability (Taecharungroj \& Mathayomchan, 2019; Chua \& Banerjee, 2013), which in turn leads to a significant number of consumer reviews. The study uses the purposive sampling method, and the condition that the selected company should meet is a specialization in one-day cultural tours in Bulgaria. The choice of the particular tour company is also based on the largest number of available reviews.

The data that was used includes all reviews for the period 2011-2017. The tour operator whose page was analyzed specializes in offering adventure and cultural tours in Bulgaria, with a large part of its portfolio consisting of one-day trips. The overall rating given by TripAdvisor reviewers by the time when the information was collected (end of 2017) is 4.5 on a 5-point scale, based on 467 reviews (TripAdvisor, n.d.), with the following shares: excellent $-82 \%$, very good $-14 \%$, average $-2 \%$, poor $-1 \%$, terrible $-1 \%$. The study included only reviews in English - a total of 365. Only the ones that refer to one-day tours were taken into account, which further reduced their number to 233 . The study went through three stages: 1) analysis of 
reviews for codes definition 2) coding the information and 3) analyzing the results. The coding process was implemented through human (the author's) interpretation, assisted by the RQDA software.

The study is qualitative, so it does not require a big sample; as Jennings (Qualitative research methods, 2012) points out, "while various authors advocate a specific number of participants for qualitative research, in reality, there is no standard. Qualitative researchers continue to amass empirical material while simultaneously interpreting/(re)constructing the empirical materials until they reach a 'qualitative informational isomorph" (Jennings, 2012, p. 316), also known as theoretical saturation. The principle of saturation in this study was applied in the first stage (identification of codes) and was reached after the twenty-first review, after which no new codes were identified. The requirement for a larger number of reviews was set to allow quantification of results and ranking of the identified attributes.

\section{Results and discussion}

As mentioned in the previous paragraph, the study goes through three major stages, and the first one involved processing $10 \%$ of the data to encode quality information (open coding). 24 reviews (containing both positive and negative remarks) were analyzed and grouped into the following main dimensions:

- Tour guide / leader. For one-day tours, the tour leader and tour guide roles are combined - quite often (in small groups and especially in private tours), the tour leader also acts as a driver. Just as other studies on group package travel attest, the figure of the tour guide is one of the most distinct factors for tourist satisfaction.

- Organization of the trip. It refers to both the smooth running of the tour as a whole, and the individual elements of the organization such as the booking process, pace of travel, etc. The five attributes that will be used as codes are reservation, pick-up and time schedule kept, pace of travel, food, and group size.

- Attractions / activities included in the tour. This dimension refers to the assessment given by tourists to the cultural and natural sites included in the tour, as well as various additional activities. The two attributes are cultural attractions and scenery/natural attractions.

- Transport. This dimension includes mainly comments on the convenience of a used vehicle (usually a bus) and safe driving. Cleanliness and Wi-Fi on board were also mentioned.

- Value for money.

The second stage of the study includes coding of the retrieved information according to the dimensions and categories identified above. The distribution of references (mentions) per code is presented in Table 1.

Table 1

Distribution of references by code

\begin{tabular}{|c|c|c|c|}
\hline Dimension & $\begin{array}{l}\text { Attribute / } \\
\text { code }\end{array}$ & $\begin{array}{l}\text { Number of } \\
\text { references }\end{array}$ & $\begin{array}{l}\text { Share of the total } \\
\text { number of reviews }\end{array}$ \\
\hline \multirow{5}{*}{ Tour guide } & - knowledgeable & 207 & $89 \%$ \\
\hline & - friendly, patient, sociable (nice personality) & 124 & $53 \%$ \\
\hline & - good narrator / sense of humor & 59 & $25 \%$ \\
\hline & - speaks good English & 50 & $21 \%$ \\
\hline & - passionate / enthusiastic & 42 & $18 \%$ \\
\hline \multirow{5}{*}{ Trip organization } & - reservation & 42 & $18 \%$ \\
\hline & - pick-up and time schedule kept & 88 & $38 \%$ \\
\hline & - food & 66 & $28 \%$ \\
\hline & - pace of travel & 63 & $27 \%$ \\
\hline & - group size & 57 & $24 \%$ \\
\hline \multirow{2}{*}{ Attractions } & - cultural sites & 142 & $61 \%$ \\
\hline & - nature / scenery & 56 & $24 \%$ \\
\hline
\end{tabular}




\begin{tabular}{|c|c|c|c|}
\hline Dimension & $\begin{array}{l}\text { Attribute / } \\
\text { code }\end{array}$ & $\begin{array}{l}\text { Number of } \\
\text { references }\end{array}$ & $\begin{array}{l}\text { Share of the total } \\
\text { number of reviews }\end{array}$ \\
\hline \multirow{4}{*}{ Transport } & - comfortable & 48 & $21 \%$ \\
\hline & - safe driving & 27 & $12 \%$ \\
\hline & - Wi-Fi & 13 & $6 \%$ \\
\hline & - clean & 7 & $3 \%$ \\
\hline Value for money & - price/value & 38 & $16 \%$ \\
\hline
\end{tabular}

The first well-expressed dimension of salient attributes of one-day tours is the performance of the tour guide / tour leader (according to the Bulgarian legislation, the two concepts overlap). Not only is it mentioned in almost $100 \%$ of the reviews, but in some of them it is cited as a key factor, and its importance is explicitly emphasized:

'The success of any tour depends on a variety of factors but must include a good guide.' (Rumples, reviewed June 25, 2015).

'Our tour guide, Martin did a really good job and this is much appreciated. On this trip I realised how important the tour guide is; everything else is just information that you can find on your own, but the guide can make the difference.' (Lina L, reviewed on June 30, 2015).

'We felt that the guide definitely added a great deal of value for us.' (budgettraveler8, June 2012).

On the other hand, there are also reviews where dissatisfaction is directly attributed to poor guiding service: 'We were 10+ people and not satisfied at all, mostly because of the guide, not the tour itself, which is fine and could be brilliant with the right guide' (fvanstra, November 2016).

The above allows us to assume that the tour guide's performance is a one dimensional factor according to the Kano model (Kano et al., 1984) - it has a serious positive or negative influence directly related to high or low perceived quality. The most frequently mentioned attribute of tour guiding is the one connected with knowledge - 207 references, with the most used words being 'knowledgeable' and 'informative'. Knowledge usually refers not only to the sites that are included in the tour, but to the country and its history: 'Martin was a great tour guide and highly knowledgeable, was able to explain everything we saw and have more in-depth discussion about the country and its history' (MarcusC1258, reviewed on October 29, 2017). This breadth of scope is extended to every aspect of Bulgarian culture and everyday life: 'His knowledge of all things Bulgarian was outstanding' (Yvone M, reviewed on August 21, 2017). The latter comments are indicative of the need to not only give information on the sites visited, but also to introduce tourists to the culture of the country they are visiting.

Good command of English is present in a large number of reviews (21\%). This is not surprising, since the tours are targeted mainly at foreign tourists and poor level of English would greatly affect the quality of the tour guiding service.

Though less often, the inability to keep the group together is also mentioned "The guide also failed to keep the group together. So, if you were in the middle to end of the group, you missed the first part of what he was saying and people began to complain (loudly) about this" (kglb61, May 2017). As the above review shows, failing to manage the group integrity may lead to explicit complaints. No less attention is paid to the purely personal aspect of communication with the tour guide, or in other words - the personality traits, with the most mentioned characteristics being friendly, patient, and sociable. Passion and enthusiasm also seem to be valued, accounting for $18 \%$ of references.

A quality that was often mentioned and highly appreciated by informants is good narrator skills, coupled with a sense of humor: 'Her explanations of the frescos were so interesting, they came to life' (Ignatowski, reviewed 
July 12,2017). This is the bonding element of the educational and entertaining aspect and is closely related to the interpretational role of the tour guide.

These findings are in line with a recent study by Dogramadjieva et al. (2019) who identify the tour guide as the most important factor contributing to a memorable experience in city tours. The constituent characteristics (derived through thematic analysis of on-line tourist reviews) are almost identical to the findings of this study: 1) skills and knowledge, and 2) personal traits, the latter being further divided into friendly, funny, helpful, and passionate.

In a more general perspective, soft skills are considered a part of the professional expertise in tourism, and among these, effective communication, hospitality, customer focus and commitment are highly rated (Kiryakova-Dineva et al., 2019).

The second most frequently mentioned dimension is the overall organization of the trip. There are several subgroups within this really broad concept. The booking process is mentioned in $18 \%$ of the comments, one of reviewers stating that it is extremely important when you are in a foreign country, where communication by telephone, for example, can be difficult. 38\% of all comments include feedback on the organization when starting / leaving the trip, the specific elements being: timely pick-up / return and convenient / easy-to-find leaving point. Almost one-third of reviewers (27\%) discuss the pace of the trip - it is highly appreciated if there is a balanced time allocation and lack of hurry, as well as the opportunity for leisure time within the program.

Food is the second most commented element of the overall tour organization, accounting for $28 \%$ of all references. Some of the elements discussed include tastiness, opportunity for tasting local food, scenic setting. The time of dining, the arrangements, and its place in the tour schedule is also considered to have impact on overall satisfaction: 'Lunch was at a restaurant near the Monastery, we stopped before heading for the Monastery to order food and when coming back the food was ready, a smart planning. '(Maria V, Spain, reviewed May 13, 2015). Some reviews also mention the educational aspect of the food experience: 'We were taken to an amazing restaurant and he was able to make local suggestions about specialties and give us a little gastronomy education.' (Cheymaybell, Australia, reviewed January 14, 2014). Last, but not least, food is seen as an opportunity for socializing and it is important that it is given the necessary attention and time: 'He was never rushing us and we enjoyed lunch and conversation together.' (JaniceS42, Canada, reviewed September 25, 2012).

Group size as a subcategory of tour organization is mentioned in $24 \%$ of reviews. While in some cases reviewers only mention the number of visitors, there are several instances when the importance and the effects of group size are discussed. Quite expected, smaller groups give the opportunity for a personalized service, establishment of closer relation between tourists/tourists and the guide, and a more relaxed atmosphere, which are all reflected in reviews: 'We were in a small group (4 including our guide) and this was to the benefit of the day because the tour could be tailored around what we were most interested in.' (Rob587, UK, reviewed August 2014). 'Perfect size that allows us to talk and not be rushed though the tour.'

Naturally, attractions/landmarks (cultural and natural sites) are the backbone of every tourist trip and are expected to play a significant role in shaping consumer satisfaction. What is noticeable in comments, however, is that much less attention is paid to the sites visited, especially when compared to the tour guide. Feedback on visited sites is generally limited to describing them as 'astounding' and 'impressive'.

Transport/comfort of vehicle was identified as another major dimension of one-day tours, with possible high impact on satisfaction. There are both positive and negative comments in the reviews and the most frequently commented features are comfort (48 references), safe driving (27 references), Wi-Fi access (13 references), and cleanliness (7 references). Complaints include inadequate space ('crowded bus'), uncomfortable seats (one of the comments mentions that even the seats in the low budget airlines are more comfortable), lack of airconditioning, insufficient vehicle power, resulting in slower travel and waste of time, and non-professional / unsafe driving.

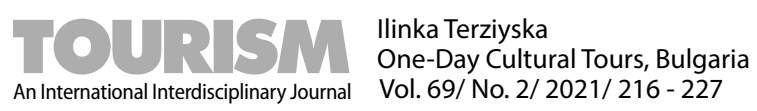


Value for money/price is the last dimension identified through the open coding. Its occurrence rate is not very high - it is mentioned in only 16 percent of reviews and is usually described by the adjectives 'affordable', 'reasonable', 'not expensive', and 'competitive'.

The model presented above shares some features with previous research, but at the same time differs from all of them to a sufficient degree so as to be considered a new framework for studying and assessing customer satisfaction with regard to one-day package tours. The most obvious reason for this is that all previous studies are focused on multiple-day tours, whose features are not the same as one-day trips (the latter being characterized by lack of overnight stay/accommodation, different trip duration leading to the necessity to pack more activities/experiences within a much more limited time span, more intensive communication with the tour leader, etc.). The main features of the proposed model that distinguish it from others can be summarized as follows:

(1) Different method - the model was generated through open coding (thematic analysis) based on online customer reviews. Most other models are based on participant observation and critical incident technique.

(2) While not so detailed as other models (e.g. Huang et al (2009)), it is tailored to a specific type of product (one-day cultural tours) and contains only the factors relevant to this category. The smaller number of factors makes it easier to conduct a quantitative survey, as longer questionnaires where some of the questions are irrelevant deter respondents from completing them.

(3) Different grouping of dimensions/attributes - e. g. restaurant / food is seen as a part of the overall tour organization process, rather than being a separate category. The analysis of reviews showed that that dining was seen as a part of the tour organization and was strongly associated with tour planning and management, rather than perceived as a separate dimension.

(4) There are attributes that are not present in the some of the existing models - group size, booking process, pace of travel, value for money. While Laesser (2008) has included group size as a factor, recent models (Bowie \& Chang, 2016), (Wang, Hsieh, \& Huan, 2000) do not have it.

\section{Conclusion}

One of the main findings of the study is that based on its high level of saliency, the tour guide is most probably the attribute of one-day tours that plays a crucial role in forming consumer satisfaction. Not only are the impressions of the guide's performance present in almost $100 \%$ of the comments, but in most cases the guiding service is explicitly referred to as the main cause of the high (or, respectively, low) level of satisfaction. The impact of the tour guiding service overshadows cultural and natural attractions, which is an unexpected result and establishes the primary role of interpretation in cultural tourism. This is contrary to some studies that found no direct effect of tour guide performance on overall satisfaction (Huang et al., 2009). The other four categories identified as a result of the analysis are transport, travel organization, visited sites/cultural attractions, and value for money. The results thus obtained can be a good basis for creating a model of tourist satisfaction in one-day package tours, although additional quantitative research is required to validate the factors and indicators, as well as to determine the degree of significance for each of them.

In purely practical terms, information can be used by providers of this type of service to improve the quality of the product offered so that it meets the needs and requirements of customers. Because of the short duration of the trip (one day), which is usually coupled by a short overall stay of tourists, it is important not only to offer visits to valuable cultural attractions, but also to use them as a basis for familiarizing visitors with the history and culture of the country as a whole - including everyday life. An equally important consumer requirement is the search for a memorable and pleasant experience, which is mainly provided through the interaction with the tour guide, where his/her professional expertise (knowledge) and personal traits are both important. Ensuring high quality of the technical aspects of the trip (convenient pick-up, keeping the time-schedule, balanced pace of travel, smaller group size, etc.) is also a determining factor for keeping high 
levels of satisfaction. As most of the tourists involved in one-day tours are foreigners, excellent command of English and user-friendly and safe booking process will be more important compared to other types of tours.

The findings of this study can be used as a backbone for a model of satisfaction attributes tailored specifically for one-day tours provided by ground operators. They were identified using a qualitative approach, which has its greatest advantage in being a preferred method for deriving new information and reducing response bias. Additional research is however needed to establish priorities between attributes, and future studies could employ quantitative methods for identifying attribute significance.

The main limitation of the study refers to its low level of generalizability - it refers to a specific setting (one day-cultural tours in Bulgaria) and findings may not refer to a different context. Mirroring the research for different destinations will prove (or reject) the universal applicability of its findings.

\section{References}

Alegre, J., \& Garau, J. (2010). Tourist satisfaction and dissatisfaction. Annals of Tourism Research, 37(1), 52-73.

Alpert, J., Myers, H., \& Mark, I. (1977). Semantic confusion in attitude research: Salience vs. importance vs. determinance. In W.D. \& J. Perreault (Eds.), Advances in consumer research, Volume 04 (pp. 106-110). Association for Consumer Research.

Alpert, M.I. (1971). Identification of determinant attributes: A comparison of methods. Journal of Marketing Research, 8(2), 184-191.

Bianchi, C. (2016). Solo holiday travellers: Motivators and drivers of satisfaction and dissatisfaction. International Journal of Tourism Research, 18, 197-208.

Bordalo, P., Gennaioli, N., \& Shleifer, A. (2013). Salience and consumer choice. Journal of Political Economy, 121 (5), 803-843.

Bowie, D., \& Chang, J.C. (2016). Tourist satisfaction: A view from a mixed international guided package tour. Journal of Vacation Marketing, 11(4), 303-322.

Boyatzis, R.E. (1999). Transforming qualitative information: Thematic analysis and code. Sage.

Brandano, M., Osti, L., \& Pulina, M. (2019). How motivations and satisfaction influence wine tourists' loyalty? An analysis of the Italian case. International Journal of Culture, Tourism and Hospitality Research, 13(1), 55-69.

Brown, V., \& Clarke, V. (2006). Using thematic anaysis in psychology. Qualitative Research in Psychology, 3(2), 77-101.

Bulatovic, I. (2020). Testing a holistic model of tourist destination loyalty. Tourism: An International Interdisciplinary Journal, 68(3), 354-358.

Çetinkaya, M.Y., \& Öter, Z. (2016). Role of tour guides on tourist satisfaction level in guided tours and impact on re-visiting intention: A research in Istanbul. European Journal of Tourism, Hospitality and Recreation, 7(1), 40-54.

Chan, A., Hsu, C.H., \& Baum, T. (2015). The impact of tour service performance on tourist satisfaction and behavioral intentions: A study of Chinese tourists in Hong Kong. Journal of Travel \& Tourism Marketing, 32(1-2), 18-33.

Chang, J.-C. (2009). Taiwanese tourists' perceptions of service quality on outbound guided package tours: A qualitative examination of the SERVQUAL dimensions. Journal of Vacation Marketing, 15(2), 165-178.

Chang, K.-C. (2012). Examining the effect of tour guide performance, tourist trust, tourist satisfaction, and flow experience on tourists' shopping behavior. Asia Pacific Journal of Tourism Research, 19, 219-249.

Chon, K., \& Olsen, M. (1991). Funtional and symbolic approaches to consumer satisfaction/dissatisfaction. Journal of the International Academy of Hospitality Research, 28, 1-20.

Chua, A.Y., \& Banerjee, S. (2013). Reliability of reviews on the Internet: The case of TripAdvisor. In Proceedings of the World congress on engineering \& computer science. San Francisco.

Cohen, E. (1985). The tourist guide: The origins, structure and dynamics of a role. Annals of Tourism Research, 12(1), 5-29.

Dogramadjieva, E., Petkova, E., \& Mitova, R. (2019). Innovative guided tours of Sofi a city as a tourist experience: Analysis of customers online reviews. In The contemporary trends in tourism and hospitality 2019: Get ready for igeneration (pp. 135-146). Novi Sad. 
Erciyas, F.Ö., \& Yıldız, M.S. (2018). Analysis of the customer experiences with netnographic investigation: A Cappadocia region five-star hotels case. Journal of Travel and Hospitality Management, 15(3), 590-602.

Guo, Y., Wang, Y., \& Wang, C. (2019). Exploring the salient attributes of short-term rental experience: An analysis of online reviews from Chinese guests. Sustainability, 11(16), 4290.

Heide, M., Gronhaug, K., \& Engset, G.M. (1999). Industry specific measurement of consumer satisfaction: Experiences from the business traveling industry. International Journal of Hospitality Management, 18(2), 201-213.

Heinonen, K., \& Medberg, G. (2018). Netnography as a tool for understanding customers: Implications for service research and practice. Journal of Services Marketing, 32(6), 657-679.

Hsieh, S., O'Leary, J., \& Morrison, A. (1994). A comparison of package and non-package travelers from the United Kingdom. Journal of International Consumer Marketing, 6(3/4), 79-100.

Huang, S., Hsu, C., \& Chan, A. (2009). Tour guide performance and tourist satisfaction: A study of package tours in Shanghai. Journal of Hospitality \& Tourism Research, 34(1), 3-33.

Ismail, A.R., Melewar, T., \& Woodside, A. (2010). A netnography study to uncover the underlying dimensions of customer experience with resort brands. Brunel University Research Archive (BURA). http://bura.brunel.ac.uk/handle/2438/4277

Jennings, G.R. (2012). Qualitative research methods. In L. Dwyer, A. Gill, \& N. Seetaram (Eds.), Handbook of research methods in tourism: Quantitative and qualitative approaches (pp. 291-324). Edward Elgar Publishing Limited.

Johnson, M., Anderson, E., \& Fornell, C. (1995). Rational and adaptive performance expectations in a customer satisfaction framework. Journal of Consumer Research, 21, 696-705.

Johnston, R. (1995). The determinants of service quality: Satisfiers and dissatisfiers. International Journal of Service Industry Management, 6(5), 53-71.

Joppe, M., Martin, D., \& Waalen, J. (2001). Toronto's image as a destination: A comparative importance satisfaction analysis by origin. Journal of Travel Research, 39(3), 252-260.

Kano, N., Seraku, N., Takahashi, F., \& Tsuji, S. (1984). Attractive quality and must-be quality. Hinshitsu, 14(2), 38-48.

Kiryakova-Dineva, T., Kyurova, V., \& Chankova, Y. (2019). Soft skills for sustainable development in tourism: The Bulgarian experience. European Journal of Sustainable Development, 8(2), 57-68.

Kozak, M. (2003). Measuring tourist satisfaction with multiple destination attributes. Tourism Analysis, 7, 229-269.

Kozak, M., \& Rimmington, M. (2000). Tourist satisfaction with Mallorca, Spain, as an off-season holiday destination. Journal of Travel Research, 38, 260-269.

Kozinets, R., Dolbec, P.Y., \& Earley, A. (2014). Netnographic analysis: Understanding culture through social media data. In U. Flick (Ed.), Handbook of qualitative data analysis. Sage.

Krech, D., \& Crutchfield, R.S. (1948). Theory and problems of social psychology. McGraw-Hill.

Kuo, N.-T., Chang, K.-C., Cheng, Y.-S., \& Lin, J.-C. (2016). Effects of tour guide interpretation and tourist satisfaction on destination loyalty in Taiwan's Kinmen battlefield tourism: Perceived playfulness and perceived flow as moderators. Journal of Travel \& Tourism Marketing, 33(1), 103-122.

Laesser, C. (2008). Predicting packaged holiday purchases: The case of a mature market (Switzerland). In Proceedings of the Australian and New Zealand Marketing Academy conference (pp. 1-7). Australian and New Zealand Marketing Academy.

Liu, P., \& Tse, E.C.-Y. (2018). Exploring factors on customers' restaurant choice: An analysis of restaurant attributes. British Food Journal, 120(10), 2289-2303.

Lu, W., \& Stepchenkova, S. (2012). Ecotourism experiences reported online: Classification of satisfaction attributes. Tourism Management, 33(3), 702-712.

MacKay, K.J., \& Crompton, J.L. (1990). Measuring the quality of recreation services. Journal of Park and Recreation Administration, 8(3), 47-56.

MacMillan, I., \& McGrath, R.G. (1996). Discover your products' hidden potential. Harvard Business Review, 74(3), 58-73.

Marcussen, C.H. (2011). Determinants of tourist satisfaction and intention to return. Tourism: An International Interdisciplinary Journal, 59(2), 203-221.

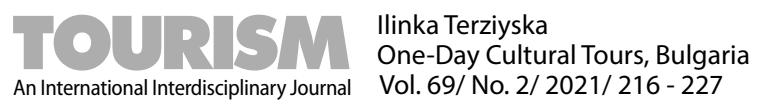


Marinao, E. (2017). Determinants of satisfaction with the tourist destination. In L. Butowski (Ed.), Mobilities, tourism and travel behavior - Contexts and boundaries (pp. 35-57). IntechOpen.

Matzler, K., Bailom, F., Hinterhuber, H.H., Renzl, B., \& Pichler, J. (2004). The asymmetric relationship between attribute-level performance and overall customer satisfaction: A reconsideration of the importance-performance analysis. Industrial Marketing Management, 33(4), 271-277.

Mikulić, J., \& Prebežac, D. (2016). The Kano model in tourism research: A critical note. Annals of Tourism Research, 61, $25-27$.

Oliver, R.L. (1997). Satisfaction: A behavioral perspective on the consumer. McGraw-Hill.

Reisinger, Y., \& Turner, L.W. (2002). The determination of shopping satisfaction of Japanese tourists visiting Hawaii and the Gold Coast compared. Journal of Travel Research, 41(2), 167-176.

Ross, E.L., \& Iso-Ahola, S.E. (1991). Sightseeing tourists' motivation and satisfaction. Annals of Tourism Research, 18(2), 226-237.

Ryu, K., Lee, H.-R., \& Kim, W. G. (2012). The influence of the quality of the physical environment, food, and service on restaurant image, customer perceived value, customer satisfaction, and behavioral intentions. International Journal of Contemporary Hospitality Management, 24(2), 200-223.

Saleh, F., \& Ryan, C. (1992). Client perceptions of hotels, a multi-attribute approach. Tourism Management, 2, $163-168$.

Shafi ee, M.M., Tabaeeian, R.A., \& Tavakoli, H. (2016). The eff ect of destination image on tourist satisfaction, intention to revisit and WOM: An empirical research in Foursquare social media. In 10th International conference on e-commerce in developing countries: With focus on e-tourism (ECDC). Institute of Electrical and Electronics Engineers (IEEE).

Taecharungroj, V., \& Mathayomchan, B. (2019). Analysing TripAdvisor reviews of tourist attractions in Phuket, Thailand. Tourism Management, 75, 550-568.

Tavakoli, R., \& Wijesinghe, S.N. (2019). The evolution of the web and netnography in tourism: A systematic review. Tourism Management Perspectives, 29, 48-55.

Taylor, S., \& Thompson, S. (1982). Stalking the elusive "vividness" effect. Psychological Review, 89(2), $155-181$.

Terziyska, I. (2017). Antecedents of consumer satisfaction from one-day cultural tours. Black Sea tourism forum: Local identity and global tourism. Slavena.

Tontini, G., \& Bento, G. D. (2020). Integration of customers spontaneous comments with overall assessment of hospitality services. Current Issues in Tourism, 23(24), 3025-3033.

TripAdvisor. (n.d.). TripAdvisor. https://www.tripadvisor.com/Attraction_Review-g294452-d2050151-Reviews-Traventuria_Day_Tours-Sofia_Sofia_Region.html

Tussyadiah, I.P., \& Zach, F. (2017). Identifying salient attributes of peer-to-peer accommodation experience. Journal of Travel \& Tourism Marketing, 34(5), 636-652.

Wang, K.-C., Hsieh, A.-T., \& Huan, T.-C. (2000). Critical service features in group package tour: An exploratory research. Tourism Management, 21(2), 177-189.

Xiang, Z., Schwartz, Z., Gerdes Jr., J. H., \& Uysal, M. (2015). What can big data and text analytics tell us about hotel guest experience and satisfaction? International Journal of Hospitality Management, 44, 120-130.

Yoon, Y., \& Uysal, M. (2005). An examination of the effects of motivation and satisfaction on destination loyalty: A structural model. Tourism Management, 26(1), 45-56.

Submitted: February 06, 2020

Revised: July 24, 2020

Revised: October 20, 2020

Revised: October 30, 2020

Accepted: November 26, 2020

Refereed Anonymously

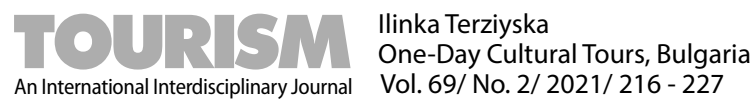

